\title{
Epidemiological survey on schistosomiasis caused by Schistosoma haematobium and Schistosoma mansoni in primary schools in the Sub-Division of Taïbong-Dziguilao, Far-North Region Cameroon
}

\author{
Dankoni Nana 1,4, Saotoing P. ${ }^{2}$, R. Tchawé2, V. Koé2, JL Ndikwé2, AM. Njan Nlôga 3 and R. Moyou Somo 4. \\ 1: Far North Regional Research and Innovation Center, Maroua, Cameroon \\ 2: The University of Maroua, Higher Teachers' Training College, Department of Life and Earth Sciences \\ 3: The University of Ngaoundere, Faculty of Science, Department of Biological Sciences \\ 4: Institute of Medical Research and Medicinal Plants Studies (IMPM), Yaoundé, Cameroon \\ Corresponding author: nanaesther65@yahoo.fr
}

Original submitted in on $25^{\text {th }}$ April 2015. Published online at www.m.elewa.org on $30^{\text {th }}$ June 2015 http://dx.doi.org/10.4314/jab.v90i1.10

\begin{abstract}
Objective: To assess the current state of schistosomiasis (Schistosoma haematobium and Schistosoma mansoni) in Taïbong Sub Division, in Mayo-Kani Division, an epidemiological survey was conducted from September to November 2014 in four government primary schools, to determine the prevalence of these human parasites.

Methodology and results: 360 pupils responded to a previously developed questionnaire and underwent urine and stool tests. The examination of urinary sediment and stool samples under the microscope revealed a prevalence of $05.83 \%(21 / 360)$ of bladder schistosomiasis caused by S. haematobium and $1.11 \%(04 / 360)$ of intestinal schistosomiasis caused by S. mansoni. The age groups of $9-11$ years had the highest prevalence rate with $7.5 \%(09 / 120)$; while the prevalence rate in the age group of $6-8$ years was $5.83 \%(07 / 120)$ and the lowest was the age group 12-14 years with (4.17\%) (05/120).A non-significant difference $(x 2=0.21, d f=1, p>0.05)$ was noted between the sexes. Girls and boys presented the same proportions in terms of infestation with $S$. haematobium $(5.81 \%$; $10 / 172)$ for girls against $(5.85 \%$; $11 / 188)$ for boys. The public primary school Dziguilao II is the most affected by schistosomiasis with (10/90; $11.11 \%)$.

Conclusion: This study assessed the current level of endemicity of urogenital and intestinal schistosomiasis in human populations of this mixed focus and permitted to put in place adequate means of perpetual control of these parasitic diseases.
\end{abstract}

Keywords: Epidemiological survey, Schistosomiasis, prevalence, pupils, Taïbong, Cameroon

\section{INTRODUCTION}

Schistosomiasis is a parasitic disease caused by flatworms; the bilharzias or schistosomes, which are bloodsucker trematodes with separated sexes living in the circulatory system (Bonnard et al., 2000). Contamination is through broken skin, when in contact with waters infested by furcocercariae (Bronstein et al., 2003). Like malaria, schistosomiasis is one of the most common human parasitic diseases in the world (Mayaka, 2001; OMS, 2013). An estimate 600 to 779 million people risk 
infection, and about 200 to 209 million are really infected (OMS, 2012). Intestinal parasitic infections globally affects more than 2 billion people worldwide, among which 300 million are severely affected, with 155000 deaths per year (Crompton, 1993) and about 200000 to 300000 are estimated in SubSaharan Africa (OMS, 2013). Largest numbers of cases are observed in Sub-Saharan Africa, America, China and East Asia (OMS, 2008; OMS, 2013). Schistosomiasis currently cover 76 countries worldwide, with over 200 million people and 600 million at risk of infection (Njiokou et al., 2004; Tchuem Tchuente, 2005). In Cameroon, three forms of schistosomiasis occur. The first presentation of their distribution was carried out in 1968 (WHO, 1991). This was a zonation map for Schistosoma haetomatobium, Schistosoma mansoni and Schistosoma intercalatum foci. More studies have shown that schistosomiasis affects several regions in Cameroon, the most relevant are: Adamawa, North, Far North, South West and Littoral (PNLH, 2009, Saotoing et al., 2011, Saotoing et al., 2014). In the

\section{MATERIALS AND METHODS}

Presentation of the area of study: The site chosen for the study is Taïbong Sub Division in the Far North Region of Cameroon (Figure 1). This unit is located in the MayoKani Division, with Kaele as the administrative headquarter. Taïbong Sub Division is located at $160 \mathrm{~km}$ South-East of Maroua and covers an area of $364 \mathrm{~km}^{2}$. The population is estimated to be 50,484 inhabitants with a density of 191 inhabitants per $\mathrm{km}^{2}$. Men account for $46 \%$ and women 54\% (Taïbong Council, 2013). This area comprises $99 \%$ of Toupouri; the population is mainly made up of farmers and cattle rearers, crafts and small businesses. The climate of the area is Soudano-Sahelian
Far North Region, previous studies have revealed the presence of these infections whose prevalence is unequally distributed. Children are the most vulnerable age groups for this disease (Saotoing et al., 2011). Thus, a study of the prevalence of urinary and intestinal schistosomiasis in some public schools in Taïbong has shown the necessity to develop appropriate control strategies of the parasite among children. The study involved more specifically public schools of Dziguilao II, Barlang, Goundaye I and Golonghini II, due to their geographical position. The aim of this study is to determine the prevalence of urinary and intestinal schistosomiasis in schoolchildren of Taïbong-Dziguilao Sub Division and especially to:

-Determine the infestation rate of urinary and intestinal schistosomiasis in schools;

-Make a distribution of prevalence by sex, age and school;

-Propose methods of struggle against schistosomiasis caused by Schistosoma haematobium and Schistosoma mansoni.

type, characterized by two seasons: a short rainy season and a long dry season. The average annual rainfall is about $800 \mathrm{~mm}^{3}$. The average annual temperature is about $27^{\circ} \mathrm{C}$ with annual amplitude of $8^{\circ} \mathrm{C}$, a minimum of $21^{\circ} \mathrm{C}$ and a maximum of $45^{\circ} \mathrm{C}$ (Communal Development Plan Dziguilao (PNDP-EN)). Taibong is built on a plain surface and the relief is low rugged. Taibong Sub Division is crossed by two rivers: the river Mbraodong that is the natural boundary between the Republic of Cameroon and the Republic of Chad, and that of Dziguilao, which originates in its surroundings. 


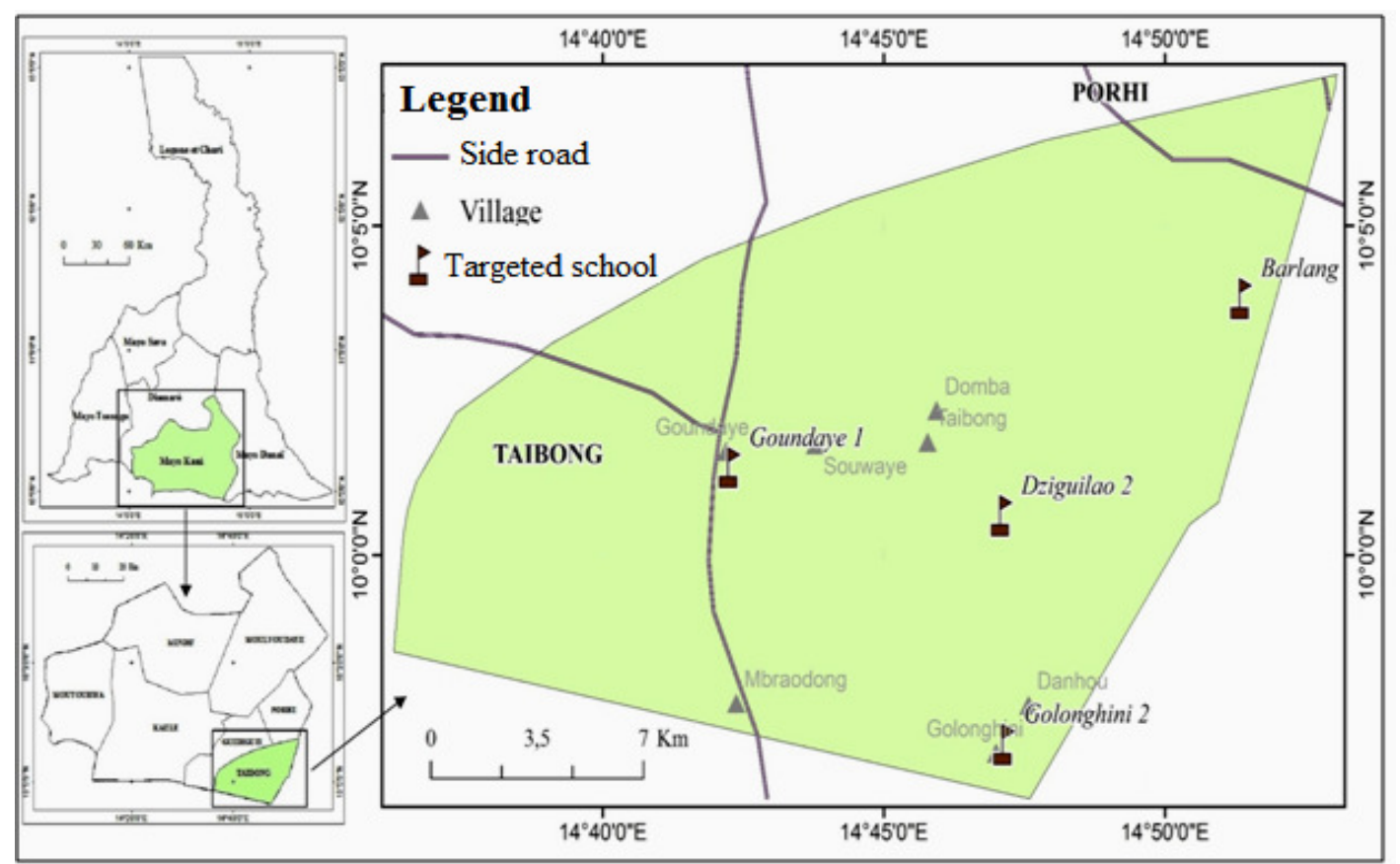

Figure 1: Location of Taïbong Sub Division and targeted schools (Image from Digital globe 2015, Base map NIC, 2014)

\section{Methodology}

Selected schools and criteria of inclusion of pupils: The study was conducted in 4 Primary Schools, which are: Dziguilao II, Goundaye I, Golonghini II and Barlang. The criteria for the inclusion of pupils in the study were: to have been born and to have been living in Taibong Subdivision; in case of migration, to have been a pupil of this unit at least for one year (enough time to have an experience on the epidemiological conditions of the medium term).All classes were concerned (class 1 to class 6 ). We made this choice to cover all age groups of the primary schools. We gathered: classes 1 and 2, classes 3 and 4 , classes 5 and 6 . In each selected group, those pupils who met the criteria for inclusion in the study were randomly selected ( 15 girls and 15 boys, so 30 pupils from each group). We have 90 pupils per school targeted and 360 were successfully sampled according to those 4 schools.

Survey: The traditional leaders, Chief of District Health Center, school Directors, teachers and schoolchildren of the study area were informed a week before the beginning of the survey. From September to November 2014, a team of three investigators in possession of survey forms (appendix) questioned the pupils who met the criteria for inclusion on the symptoms of the schistosomiasis, including urinary and intestinal schistosomiasis. Transparent tubes to collect the urine and stool are distributed to children who have met the criteria a day before the operation. These tubes were labelled with a marker, the survey forms were filled with a pen and a notepad served to take some data.

Search for schistosomes eggs: Urine and stool examinations were performed at Integrated Health Center Laboratory Dziguilao.

Schistosoma haematobium: Once in the laboratory, urine was centrifuged using a manual centrifuge. The supernatant was poured and two to three drops of the urine sediment was deposited on a slide and covered with a cover slip. The set was observed using an optical microscope to the X10 objective for a clear observation of the image and after the image perception, the X40 lens for greater vision was used. For each collected urine, the same procedure was repeated three times to increase the chance to observe $S$. haematobium eggs.

Schistosoma mansoni: Each stool sample was examined by three microscopic observations (Golvan et al., 1984). The technique used was that of direct observation of stool fresh water in physiological $9 \%$, $\mathrm{NaCl}$ that enabled the identification of eggs of Schistosoma mansoni. A drop of saline $\mathrm{NaCl} 9 \%$ is deposited using a micropipette on clean slide object.

A stool fraction was withdrawn with a microspatula and diluted with physiological saline water deposited on the blade; the preparation was covered with a cover slip in order to obtain a transparent thin layer to enable the search of Schistosoma mansoni eggs. The preparation is 
observed under an optical microscope, the first X10 objective perception of the image and then the X40 objective to make sharper and clearer image; the results are recorded, corresponding to the stool samples examined.

Data analysis: To perform data analysis, Microsoft Excel 2003 and descriptive statistics (averaging, standard

\section{RESULTS AND DISCUSSION}

Sample Characteristics: Male subjects were more represented (188 boys) against (172 girls). However, the chi-square test $(x 2=2.19 ; d f=1 ; p>0.05)$ revealed a nonsignificant difference between the sexes. In fact, in some classes (Classes 5 and 6 ), the number of girls do not deviation, frequency, chi-square test) were used to determine the relationship between the sexes, age groups and schools. A risk $a=0.05$ is selected for reading the table of chi-square. The correlation coefficient (r) of Pearson, to evaluate the association between two parameters, was calculated.

reach the expected number for the female gender because of early marriage in the study area.

Average of the symptoms presented by the examined subjects: Table 1 summarizes the various symptoms experienced by pupils.

Table 1: Frequency of symptoms experienced by subjects

\begin{tabular}{lcl}
\hline Symptoms & Frequency & Percentage \\
\hline Itching & $29 / 360$ & 8.05 \\
Abdominal pain & $98 / 360$ & 27.22 \\
Diarrhoea & $32 / 360$ & 8.89 \\
Cough & $170 / 360$ & 47.22 \\
Blood in the stool & $3 / 360$ & 0.83 \\
Blood in the urine & $90 / 360$ & 25.00 \\
Pain while defecating & $11 / 360$ & 3.05 \\
Pain while urinating & $270 / 360$ & 75.00 \\
Joint pain & $7 / 360$ & 1.94 \\
Urinary frequency & $30 / 360$ & 8.34 \\
\hline
\end{tabular}

Prevalence of urinary schistosomiasis after microscopic examination: Figure $\mathbf{2}$ shows the estimated prevalence of urinary schistosomiasis in four public primary schools in Taibong Sub Division. It showed that hematuria (25\%) is a more accurate approximation to indicate the prevalence of Schistosoma haematobium. The results obtained after microscopic examinations of urine show that infected pupils were $21 / 360$, and an

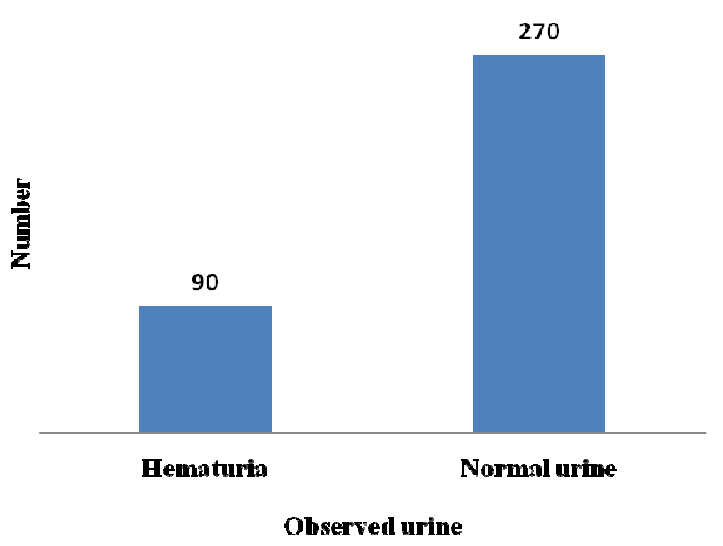

Figure 2: Theoretical Prevalence of urinary schistosomiasis in children in public schools of Taïbong Sub Division overall prevalence of $05.83 \%$ of cases of schistosomiasis caused by Schistosoma haematobium. The results of microscopic examinations confirmed the hypothesis that children with hematuria are infested with bilharzias because, on 90 students who submitted blood in their urine, 21 of them presented $S$. haematobium eggs in their urine, a prevalence of $23,33 \%(21 / 90)$. 
The correlation coefficient indicates that hematuria and subjects infested with bilharzias were perfectly correlated ( $r=0.99)$, as a subject with hematuria is significantly ill. Saotoing et al. (2011) in Maroua, Ripert et al. (1982) in Koza, Yelnik (1982) and Wibaux-CHARBOIS et al. (1982) in Yagoua conducted similar studies and found that urinary schistosomiasis is endemic in plain areas. Furthermore, Granier et al. (1985) in the Mount Mandara and OMS (1987) also revealed infection rates of about $40 \%$, due to urinary schistosomiasis around Yagoua and Maroua. Compared to this study results, a clear regression of schistosomiasis caused by $S$. haematobium is seen. This significant drop is justified by screening campaigns and distribution of praziquantel conducted by the National Programme of Struggle Helminthiasis and Intestinal Schistosomiasis (PNLSHI) and selected Non Government Organizations (NGOs). Dankoni et al. (2014) made a similar observation in Kekem and noted that the layout of the space, the installation of public fountains and wells have contributed to the decrease of contacts with contaminated waters. The awareness campaign, health education of the population and environmental remediation efforts have contributed to the decline in the spread of this infection. It should also be noted that this decline might also be influenced by climate change, in that high temperatures have a negative effect on the survival of snails, which are intermediate hosts.

Prevalence of pupils infested with $S$. haematobium in relation with age: Figure 3 below shows the prevalence of children infested with $S$. haematobium in relation with age. The age groups of 9-11 years had the highest prevalence rate with $7.5 \%(09 / 120)$; while the prevalence rate in the age group $6-8$ years was $5.83(07 / 120)$ and the lowest rate in the age group 12-14years (4.170\%) $(05 / 120)$. This uneven distribution is because children of 6-8years are not well monitored by the parents. They walk barefoot and are in constant contact with the waters of ponds and river, where intermediate hosts and furcocercariae are located. These reasons remain the same for the age group of 9-11years. However, there is also a lack of awareness of the risk incurred by bathing or wading in infested water by furcocercariae. Pupils in the age group 9-11years also practice a number of activities such as agriculture and livestock that expose them to the infestation. On contrary, pupils in the age group of 12-14 years are least infested. This may be because these children are more mature and aware of the risk they incur. Saotoing et al. (2011) conducted similar studies in some public primary schools in Maroua and found that, the most infested age group was the 9-11years (36\%) and the least infested one was that of $6-8$ years $(14.70 \%)$. In contrast, Menan et al. (1997) in Abidjan, Côte d'Ivoire, in the same situation, found that the age group 8-15 years are rather the most affected compared to the age group 3-7 years. Compared to all these results, there is a divergence in the most infested ages. One could hypothesize that there are no universally most affected age groups by the degree of endemicity of $S$. haematobium. The plausible justification could be the risks taken and the extracurricular activities done by pupils (Saotoing et al., 2011). Regarding this study, all age groups were affected by schistosomiasis, since it found that there was no statistically significant difference between the three ages group $\left(\chi^{2}=1.01 ; \mathrm{df}=2 ; p>0.05\right)$. The results were closer to the pattern commonly found where there is a peak in the age group 6-11years and a progressive decrease in the infestation as the age increases (Pieq et Rou, 1980; Brinkman et al, 1988; Traoré et al., 1990). In contrast, King et al. (2005) reported that heavy infestations were encountered more frequently in children of 0 to 14 years than adolescents and adults (30\% against $14 \%$ respectively). OMS (1998) added that, in the same vein as from epidemiological studies in different endemic areas, the prevalence and intensity of infestation increase during the first 15 years of life and then decline, indicating that the infestation attenuates gradually and is in parallel with the development of the immune system. 


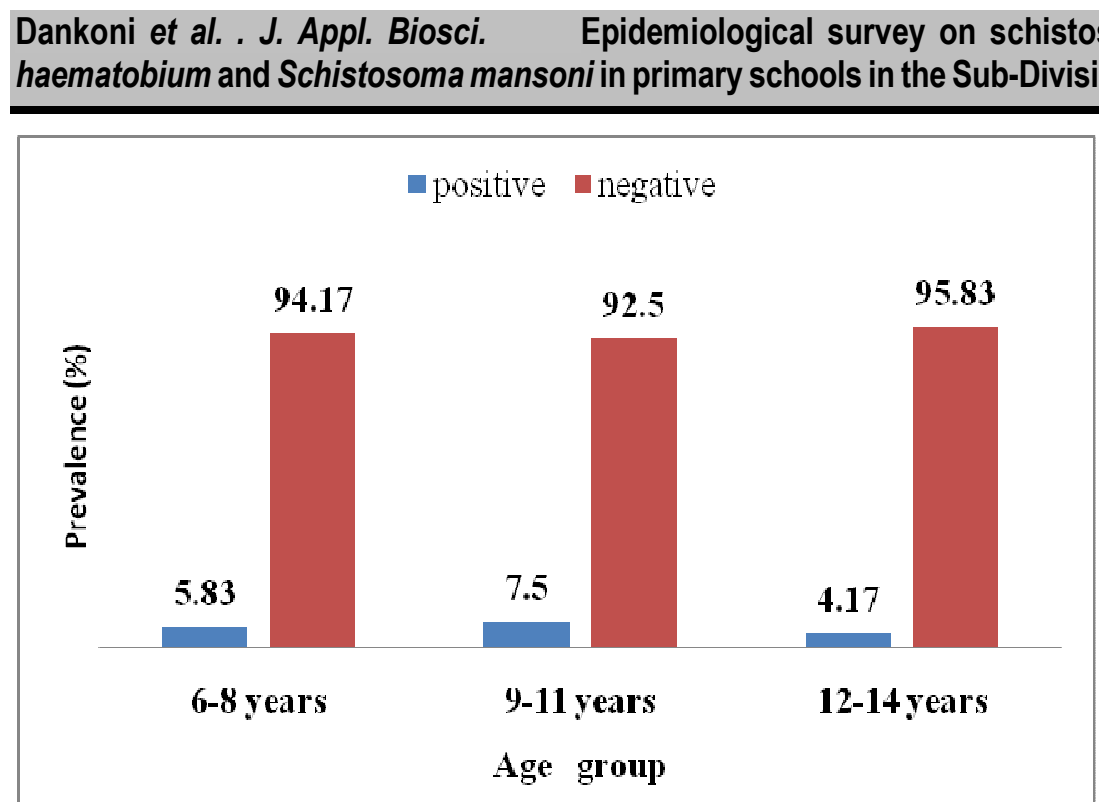

Figure 3: Prevalence of urinary schistosomiasis in relation to age groups among primary schoolchildren in Taibong Sub Division

Prevalence of urinary schistosomiasis in relation to sex: Girls and boys presented the same proportions in terms of infestation with S. haematobium (5.81\%; 10/172) for girls against $(5.85 \% ; 11 / 188)$ for boys. The gender difference was not statistically significant $\left(\chi^{2}=0.21\right.$, $\mathrm{df}=$ $1, p>0.05)$. This equal prevalence between the sexes could be justified by the fact that, in Taibong Sub Division, girls practice the same activities as boys: keeping goats and cattle, participating in farm works. In addition, some parents prevent girls for taking drugs provided by the government or by NGOs. According to these parents, these drugs would make their girls infertile or sterile. On the contrary, Traore et al. (1990) conducted similar studies and underlined that the prevalence of schistosomiasis causes by Schistosoma haematobium is significantly higher among boys than girls. Kassi (1989) explains that boys, not only bathe frequently in rivers during the rainy season, but also help their parents in farm, which are considered, infested with schistosomes. Prevalence of urinary schistosomiasis in relation to school: Figure 4 shows the distribution of the prevalence of $S$. haematobium in schools. According to this figure, the infestation rates vary from one school to another. The overall infection rate was $05.83 \%$ in the Taïbong Sub Division. The public school of Dziguilao II is the most affected (10/90; 11.11\%), despite the efforts made by the local authorities in distributing praziquantel in all the schools. Nevertheless, it seems that some leaders of primary schools do not ensure the effective taking of drugs that they distribute to pupils. In addition, some parents simply refuse their children taking these drugs. Public Primary Schools Golonghini II (4/90; 4.44\%) and Goundaye I (4/90; 4.44\%), rank second. In fact, the village of Golonghini is located in the lowland and is crossed by a river. Public Primary School of Barlang $(3 / 90 ; 3.33 \%)$ is ranked at the bottom. The results of this study are consistent with those of Mayaka (2001) at Lemfu, in the Democratic Republic of Congo, where he shows that, it is important to note that, the proximity of a village with a river is not enough to explain the different variations in infestation rates according to villages. 


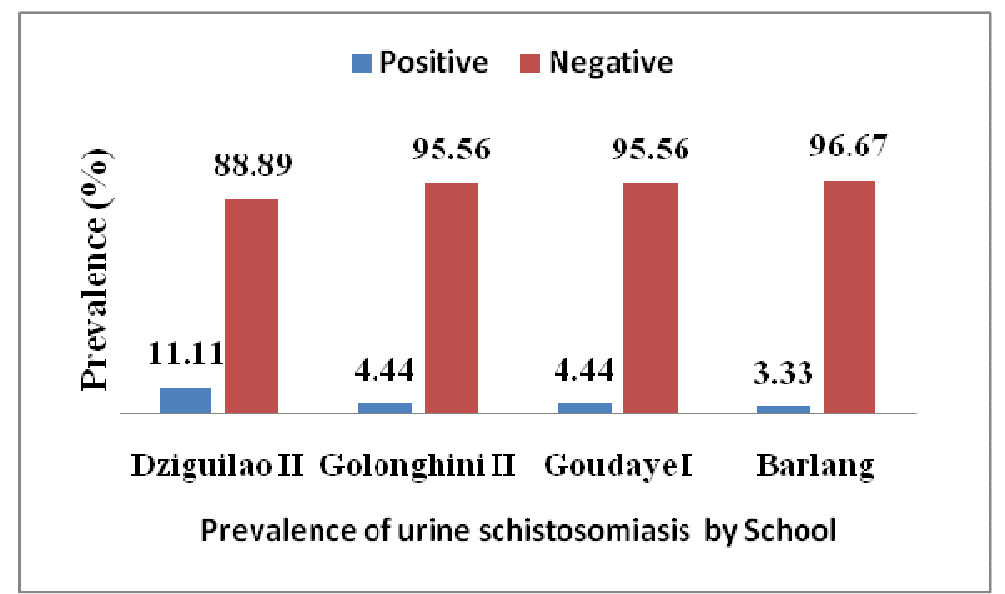

Figure 4: Distribution of the prevalence of schistosomiasis S. haematobium by school

Prevalence of intestinal schistosomiasis in Taïbong Sub Division: Only four (04) cases of intestinal schistosomiasis infection were identified in Taïbong Sub Division after microscopic examination of stool collected from children meeting the criteria for study. This is a case in Golonghini (02 females) and Barlang (02 males). This represents an overall rate of $1.11 \%$. Njiokou et al. (2004) conducted similar studies and found that intestinal schistosomiasis is spread in the Lekie Division where the infestation rate due to intestinal schistosomiasis was $5 \%$. By making a comparison with this study, results obtained in the Far North Region, the intestinal schistosomiasis decreases in this hot region. This decline in prevalence is justified by high temperatures that kill the intermediate hosts in one hand, and in the other hand, the lack of water to dilute the stool so that eggs can develop (Saotoing et al., 2014).

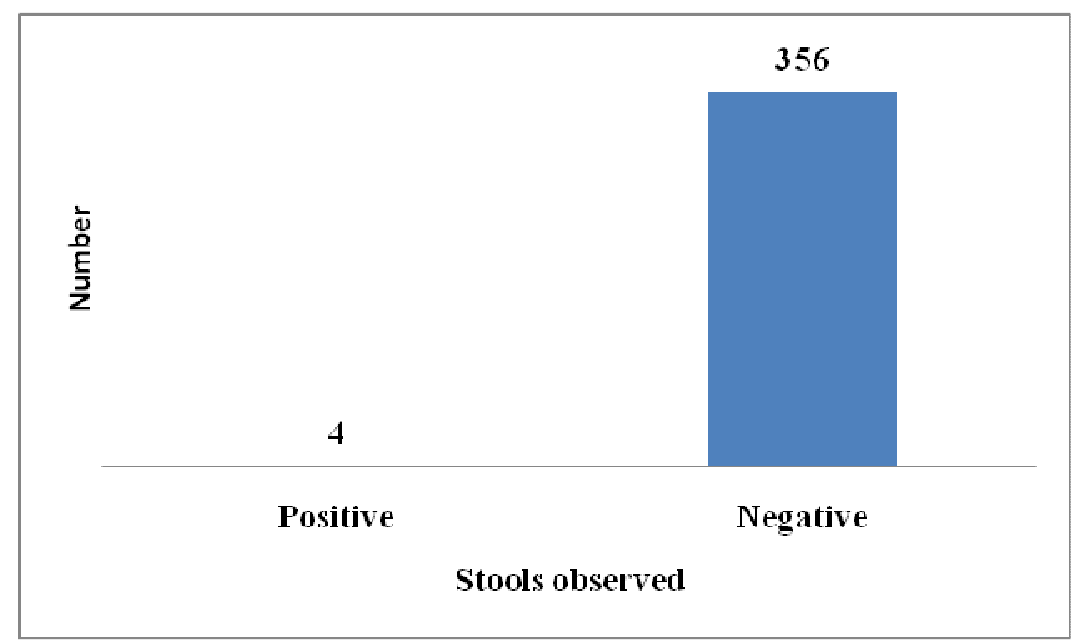

Figure 5: Prevalence of intestinal schistosomiasis

Distribution of the prevalence of pupils infested with S. mansoni by age: The Figure 6 shows that the four infested children with Schistosoma mansoni are all belonging to age group of 9-11 years. The low prevalence of Schistosoma mansoni is because, either the intermediate hosts are rare on one hand and on the other hand, the slow nature of dilution and dispersal of eggs of this species (Saotoing et al., 2014). Because of the low prevalence, it is difficult to argue that the infection depends on age. 


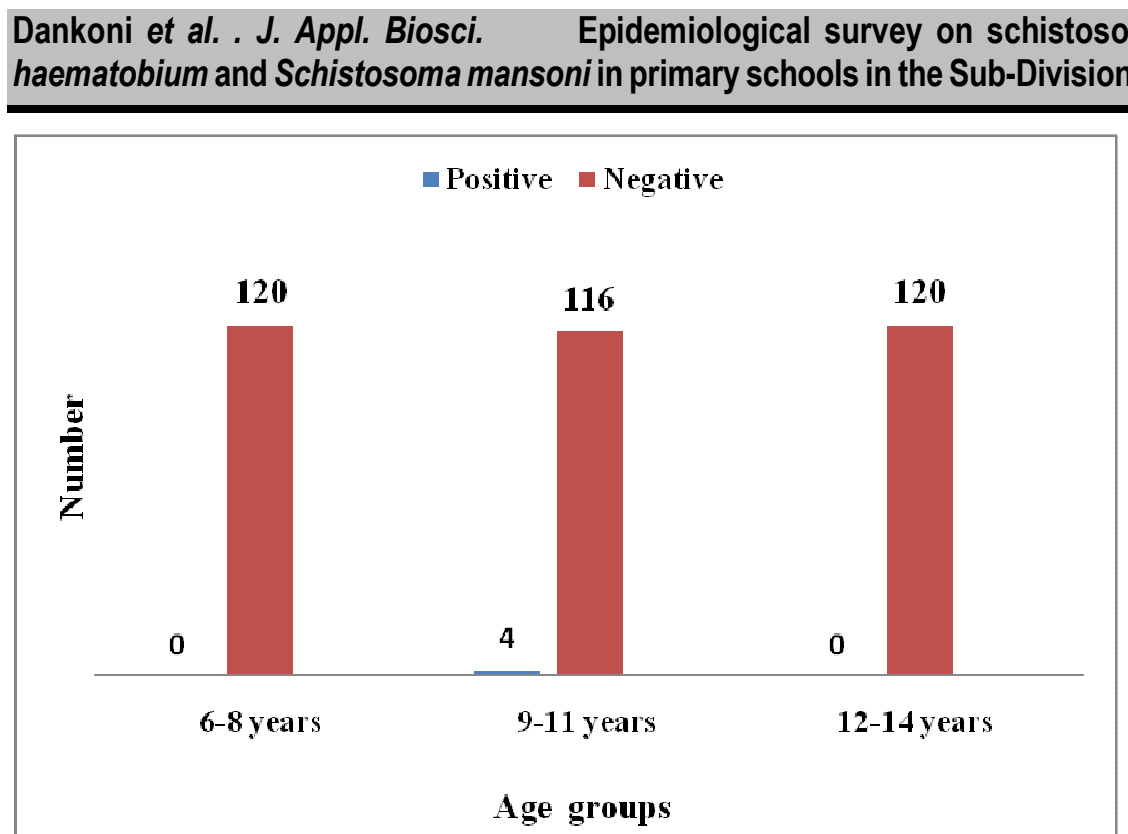

Figure 6: Distribution by age of $S$. mansoni infection rate

\section{CONCLUSION AND REMEDIATIONS}

It appears from this work that, $05.83 \%$ of children living in this Sub Division are infested with schistosomiasis caused by S. haematobium and $1.11 \%$ children infested with schistosomiasis caused by S. mansoni. The pupils in the age groups of 9-11years are more infested (7.5\%) than those of 6-8 years (5.83\%) and $12-14$ years $(4.17 \%)$. The Public Primary School Dziguilao II is the most affected $(11.11 \%)$ by $S$. haematobium, compared to $3.33 \%$ of Barlang public primary school. As for $S$. mansoni, Barlang and Golonghini II schools share the same score $(0.55 \%)$. The previous treatment against schistosomiasis will not exclude a possible reinfection, if the individuals continue to live under the same environmental conditions. Infection with S. haematobium depends on several parameters including the socioeconomic situation of parents, residence and extracurricular activities. Among the strategies against the urinary and intestinal schistosomiasis, we can make the following recommendations: - the local authorities should obtain community participation in the fight against this disease by limiting contacts after signalling the main

\section{APPRECIATION}

The authors of this article thank the Regional Delegate of Public Health of the Far North Region of Cameroon for allowing the urine and stool samples of children to be analysed. We will not fail to express our deep gratitude to the Inspector of Basic Education Taïbong Sub Division and the Directors of the schools for having facilitated our infested rivers, by the installation of water supply systems, by environmental sanitation activities (schools, villages and regular cleaning of rivers) and by a correct use of personal sanitation;

- WHO should ensure epidemiological control through its supervision team, to train primary school teachers, members of the local health committee, the nurses of Taïbong integrated health centre, in the fight against schistosomiasis by using the following measures: the dissemination of educational messages related to the transmission of the disease, the mobilization of the community for their collective actions during cleaning of rivers to increase water speed and reduce the habitats of snails;

- the scientific community should repeat the studies in this area using various stool techniques, should extend this study to other institutions and the general public and should conduct the studies in different seasons;

- the population should ensure the respect of tangible and sanitary hygiene; and ensure deworming in households.

task during data collection. Finally, we thank the Head of Integrated Health Center Dziguilao and his Laboratory Technician for their frank cooperation and active participation in the success of this work. 


\section{APPENDIX}

Survey sheet on symptoms of urinary and intestinal schistosomiasis in rural areas

\section{I- Identification}

School name

Pupils' name

Age-

Sex-

Class-

Duration in the locality

II-Symptoms

\begin{tabular}{|c|c|c|}
\hline Symptoms & & \\
\hline Itching & \multicolumn{2}{|c|}{ Yes? No? } \\
\hline Abdominal pain & Yes? & No? \\
\hline Diarrhoea & Yes? & No? \\
\hline Cough & Yes? & No? \\
\hline Blood in the stool & Yes? & No? \\
\hline Blood in the urine & Yes? & No? \\
\hline Pain while defecating & Yes? & No? \\
\hline Pain while urinating & Yes? & No? \\
\hline Joint pain & Yes? & No? \\
\hline Urinary frequency & Yes? & No? \\
\hline ratory tests & & \\
\hline tive ............. $\square$ & $\begin{array}{c}\text { Stool } \\
\text { - Positive .................. }\end{array}$ & \\
\hline ative............. $\square$ & -Negative................ &..$\square$ \\
\hline
\end{tabular}

\section{Laboratory tests}

Urine

- Positive

- Negative
-Negative

\section{Yes?}

Yes? No?

Yes? No?

Yes? No?

Yes? No? 


\section{REFERENCES}

Bonnard P., Kalach N., Candranel J-F., Remoué F., Riveau G., Capron A., 2000. Manifestations digestives et hépatiques de la bilharziose. In : " Gastroentérologie clinique et biologique." ", Masson, Paris, France, pp. 409- 419.

Brinkmann U. K., Werler C., Traoré M.., 1988. Experiences with mass chemotherapy in the control of schistosomiasis in Mali.Trop. Med.Parasitol ; 39 : 167-17.

Bronstein J.-A.,Caumes J.-L., Richecœur M., Lipovac A.S., Klotz F.,2003. Complications digestives et hépatiques des schistosomoses. In HépathoGastro. 10-6, 425-34.

Crompton D.W.T. \& Savioli L., 1993. Parasitoses intestinales et urbanisation. Bulletin de I'Organisation mondiale de la Santé, 71 (2): 143149.

Dankoni E.N et Tchuem Tchuenté L.A, 2014. Epidémiologie de la schistosomiase et des géohelminthiases dans l'Arrondissement de Kékem (Ouest- Cameroun). International Journal of Innovation and Applied Studies. Vol. 8 No. 4 Oct. 2014, pp. 1782-1790

Golvan Y. J., et P. Ambroise T., 1984. Les nouvelles techniques en parasitologie. Flammarion Médecine-Sciences 32p.

Granier H., Granier-Filloux F., Granier-Guionie M., Couprie B., Samé-Eboko A. Appriou M., Tribouley J., Ripert C., 1985. Etude épidémiologique des Bilharzioses intestinale et urinaire dans la région de Tala Mokolo (monts Mandara, Nord-Cameroun). Méd. Trop; 45(1) pp. 39-45.

Kassi E.A., 1989. Contribution à l'étude des helminthiases intestinales et urinaires en Côte d'Ivoire. Résultats obtenus en milieu scolaire dans cinq (05) localités de la région d'Aboisso. Thèse Méd. Abidjan, № 1036.

King; C.H., Dickman K, Tisch DJ, 2005. Reassessment of the cost of chronic helmintic infection: a metaanalysis of disability-related outcomes in endemic schistosomiasis. Lancet 365, 1561

Mayaka, M.S., 2001. Étude épidémiologique de la bilharziose à Schistosoma mansoni en milieu scolaire: cas du groupement de Kiyanika. Mémoire de Doctorat. Universités de Kongo. Faculté de médecine. 58p.

Menan E.I.H., Nebavi N.G.F., Adjatey T.A.K., Assavo N.N., Kiki-Barro P.C., Kone M., 1997. Profil des helminthiases intestinales chez les enfants d'âge scolaire dans la ville d'Abidjan. Bull. Soc. Path. Exot. 90: 51-54.

Njiokou F., Yimta Tsemo L.C., Kuete T., Same Ekobo A., 2004. Dynamique des Schistosomoses intestinales au Cameroun: Evolution de la transmission dans le foyer mixte de Nkolmébanga, Lékié. Med Trop; 64 : 351-354

O.M.S, 1987. Cameroun-Sao Tomé et Principe. Atlas de la répartition mondiale des Schistosomiases. CEGET- CNRS, pp. 142-151.

O.M.S, 1998. Lutte contre la schistosomiase et les parasitoses intestinales. Rapport de la consultation informelle de I'O.M.S. sur la lutte contre la schistosomiase, Genève, 2- 4 décembre 1998.

OMS, 2008. Chimioprévention des helminthiases chez l'Homme. Utilisation coordonnée des médicaments anthelminthiques pour les interventions de lutte: Manuel à l'intention des professionnels de la santé et des administrateurs de programmes.

OMS, 2012. Schistosomiase: population ayant besoin d'une chimioprévention et nombre de personnes traitées en 2010. No. 4, 87, 37-44

OMS, 2013. Relevé épidémiologique hebdomadaire №. 2, 88, 17-28

PIEQ J.J. et ROU J., 1980. Epidémiologie des Bilharzioses. Méd. Trop., 40, (1), pp 9-21.

PNLSHIC. 2005. Programme National de Lutte contre la Schistosomiase et les helminthiases Intestinales au Cameroun: plan stratégique 2005-2010. 92p.

Ripert C., Leugueun-Ngougbeou J., Samé-Ekobo A., 1982. Etude épidémiologique de la Bilharziose et des Nématoses intestinales à Bafia (Cameroun). Bulletin de la Société et pathologie Exotique, 75, pp. 55-61.

Saotoing P., Vroumsia T., Njan A. M. Tchuenguem F.N., Messi J., 2011. Epidemiological survey of schistosomiasis due to Schistosoma haematobium in some primary schools in the town of Maroua, Far North Region Cameroon. International Journal of Tropical Medicine Volume: 6(2), 19-24.

Saotoing P., Wadoube Z., NjanNlôga A-M., 2014. Epidemiological survey of urinary and intestinal schistosomiasis in Mayo-Louti Division, Northern Region Cameroon. Journal of Applied Biosciences 81:7233 - 7240 
Tchuem Tchuente L.A., 2005. Lutte contre la schistosomose: défi et perspectives pour le XXle siècle

Traoré L.K., Ouedraogo L.H., Pietra V., Nacoulma I., Nebie B., Pafadnam F.D.S., 1990. Prevalence of infection with Schistsoma haematobium and Schistosomiasis relations Hematuria in two villages in Burkina Faso. Medicine Afrique Noire, 37: 100- 107.

WHO 1991. B asic laboratory methods in medical Parasitology. World Health Organisation. Geneva.

Wibaux-Charlois M., Yelnik A., Ibrahim H., Same- Ekobo A., Ripert C., 1982. Epidemiological study of Schistomiasis Schistosoma haematobium in the perimeter Yagoua Rice (Cameroon) II. Distribution and ecology of hosts. Bull. Soc. Exotic Pathol., 75 : 72- 93.

Yelnik A., Issoufa H., Appriou M., Tribouley J., Gentilini M., Ripert C., 1982. Etude épidémiologique de la Bilharziose à Schistosoma haematobium dans le périmètre rizicole de Yagoua (Cameroun), I. Prévalence de l'infestation et évaluation de la charge parasitaire. Bulletin de la Société et pathologie Exotique, 75, pp. 62. 